\title{
TOWARDS PREPARATION OF DESIGN SPECTRA FOR SERBIAN NATIONAL ANNEX TO EUROCODE 8 - PART II: USAGE OF THE UHS APPROACH INSTEAD OF NORMALIZED SPECTRAL SHAPES SCALED BY A SINGLE PSHA PARAMETER *
}

$U D C 624.042 .7: 550.34(497.11)(083.74)=111$

\author{
Borko Đ. Bulajić ${ }^{1}$, Miodrag I. Manić ${ }^{2}$ Đorđe Lađinović ${ }^{3}$ \\ ${ }^{1}$ Highway Institute, Belgrade, Serbia \\ borkobulajic@yahoo.com \\ ${ }^{2}$ Faculty of Civil Construction Management, Union - "Nikola Tesla" University, Serbia \\ ${ }^{3}$ University of Novi Sad, Faculty of Technical Sciences, \\ Department of Civil Engineering, Serbia
}

\begin{abstract}
Eurocode 8 spectra are scaled by the peak ground acceleration values that are defined for the given site through a probabilistic seismic hazard analyses (PSHA). However, spectra that are created by combining the empirical shapes with the single PSHA-defined scaling factor will not represent the so-called Uniform Hazard Spectra (UHS). Moreover, the very shape (Type 1 or Type 2) of the Eurocode 8 elastic spectrum is selected with respect to the magnitude of the earthquakes "that will contribute most to the seismic hazard defined for the purpose of probabilistic hazard assessment...". Such definition is somewhat obscure since these "most contributing" earthquakes are, even at the same site and for the same probability i.e. for the same "return period", different (in a general case) for different vibration periods, while the whole Eurocode 8 spectrum is scaled by using only the PSHA estimate of the peak ground acceleration. In this Paper we present an illustrative example of the Uniform Hazard Spectra for the city of Belgrade and compare the obtained UHS spectra, as well as the scenario empirical spectra scaled for different earthquake parameters, to the corresponding Eurocode 8 spectra, further pointing out the intrinsic ambiguities in the current EC8 suggestions for creation of design spectra.
\end{abstract}

Key words: Eurocode 8, spectral scaling, probabilistic seismic hazard analysis, return period, Uniform Hazard Spectra.

\footnotetext{
Received October 15, 2012

* Acknowledgement: The research of the first and the third authors was partially supported by the Serbian Ministry of Education, Science and Technological Development grant no. 36043.
} 


\section{INTRODUCTION}

Although Eurocode 8 [1] leaves the option that any country can use its own shape of the spectrum after it defines it in its own National Annex, and thus compensates for the plausible deficiencies of the proposed shapes of the design spectra (these were discussed in Part I of this Paper [2]), there is yet another important issue related to the scaling of the EC8 spectra that needs to be reviewed. Namely, the Eurocode 8 spectra, however their shapes may look like, are still going to be scaled by the PGA values that are obtained as results of probabilistic seismic hazard analyses (PSHA) - the design ground acceleration on the ground type $A$ (i.e. the rock), $a_{\mathrm{g}}$, by which the Eurocode 8 elastic response spectra are scaled, is a probabilistic value, that is the value obtained after the probabilistic hazard assessment for the site ${ }^{1}$ in question. More precisely, the design acceleration, $a_{\mathrm{g}}$, represents the product of the reference peak ground acceleration, $a_{\mathrm{gR}}$ (see Articles 2.1 and 3.2.1(2), in: [1]), and the "importance factor", $\gamma_{\mathrm{I}}$ (Articles 2.1 and 3.2.1(3), in: [1]), by which the reliability differentiation is also implemented in Eurocode 8 by classifying structures into different importance classes. Reference acceleration, $a_{\mathrm{gR}}$, is associated with the reference probability of exceedance $P_{t}(A)=10 \%$ in $t=50$ years, i.e. with the return period $T_{r}=475$ years, for the no-collapse requirement (that the structural integrity and a residual load bearing capacity will be retained after the earthquake), and with the reference probability $P_{t}(A)=10 \%$ in $t=10$ years, i.e. with $T_{r}=95$ years, for the damage limitation requirement (the requirement that the costs of prospective damages are also limited). The importance factor, $\gamma_{\mathrm{I}}$, is further assigned to different importance classes (related to different types of structures), and if it is feasible this factor is to be derived so as to correspond to a higher or lower probability of exceedance of the seismic event (with regard to the reference probability) as appropriate for the design of the particular class of structures. On the other hand, shape of the Eurocode 8 elastic spectra, $S_{\mathrm{e}}(T)$ or $S_{\mathrm{ve}}(T)$, is selected with respect to the magnitude of the earthquakes "that contribute most to the seismic hazard defined for the purpose of probabilistic hazard assessment" (Note 2 in Article 3.2.2.1(5), Note 1 in Article 3.2.2.2(2)P, and Note in Article 3.2.2.3(1)P, in: [1]).

Thus, according to Eurocode 8 [1] spectral shapes are chosen with respect to the size of one or a couple of the earthquakes that dominantly influence the probabilistic seismic hazard estimate at a given location, while the whole spectrum is scaled by the value of the peak ground acceleration that should be found, for the given location, on an appropriate PSHA (Probabilistic Seismic Hazard Assessment) map that was on the other hand derived by taking into account all prospective earthquakes in the considered region. As we shall see in the following text, the problem lies in the simple fact that different ordinates of a Eurocode 8 spectrum do not have the same probability of (not) being exceed as the peak

\footnotetext{
1 There are two basic philosophies for seismic hazard analyses: the deterministic seismic hazard assessment (DSHA) and the probabilistic seismic hazard assessment (PSHA). Although there is no generally accepted deterministic approach for all parts of the world and all application areas, it can be said that the DSHA approach proposes design for only one (e.g. maximum credible) or just a few single prospective earthquakes of particular size (magnitude) and with the origin (source) at a particular distance from the considered site, while the PSHA approach on the other hand estimates the probability that a particular level of strong ground motion will be experienced or exceeded during the expected lifetime of the analyzed structure, considering all conceivable prospective earthquakes that could occur in the region surrounding the given site (for more details refer e.g. to: [3]).
} 
ground acceleration (i.e. the $T=0 \mathrm{sec}$ spectral ordinate). Instead of using such method for creation of design spectra, it is possible to carry out a probabilistic hazard analysis for each spectral ordinate by using empirical equations for scaling response spectra, and for each site in the considered region to obtain a Uniform Hazard Spectrum. In the following pages main features of the Uniform Hazard Spectra will be presented and compared (in an illustrative example) to the normalized Eurocode 8 response spectra scaled by the peak acceleration values that are obtained through probabilistic hazard analyses.

\section{Probabilistic SEISMic HaZARD AsSESSMENT AND UNIFORM HAZARd SPECTRA}

Probabilistic seismic hazard assessment is being used to calculate the probabilities of experiencing a particular level of a ground motion parameter due to all different seismic events that could occur in some area around a given structure during its estimated life period. Although there are several different methodologies that can be used for the PSHA analyses (see e.g. discussion in: [7]), for the illustrative example and all discussions in this Paper we shall use the still widely used "deductive" approach, which is called "deductive" because beside using the catalogue of historical earthquakes and the appropriate empirical attenuation equations for the region ${ }^{2}$, we are also trying to deduce what are the possible faults and earthquake sources for the selected region, as well as what are the seismicity features of these sources. The first widely available computer program for performing elementary PSHA based on the work of Cornell [8] was presented in 1976 by McGuire [9], while the first complete deductive methodology for introduction and modeling of the tectonic region, and for producing complete response or Fourier spectra having a constant probability of no exceedance ("Uniform Risk Spectra") was developed by Anderson and Trifunac [10-11]. The concept of "Uniform Risk Spectra", introduced by Anderson and Trifunac [10], was later renamed to Uniform Hazard Spectra or the UHS approach. Up to date, many variations of the deductive approach have been developed, and the detailed descriptions of the theory behind these methods can be found in numerous publications (e.g. [12-14])). Now the most important steps of the deductive method will be briefly presented, and the standard misconceptions made frequently by engineers and researchers on reliability and probabilistic nature of the obtained results will be further discussed.

The first step in any deductive PSHA method is the characterization of the various seismic sources, which may affect the given site [15-17]. After delineating the source zones and defining their focal depths, it is necessary to define the seismicity (i.e. the expected rate of occurrence of earthquakes of different size), expected to occur in each zone during a specified period of time. The seismicity is usually estimated through a least square regression analysis of the data on past earthquakes, defining the parameters $a$ and $b$ of the Gutenberg and Richter [18] recurrence relationship:

$$
\log N_{G R}(M)=a-b M,
$$

\footnotetext{
${ }^{2}$ The ground motion attenuation relations are equations specifying the values of the selected ground motion parameter at a particular site, as a function of: earthquake size, distance from the earthquake source to the site, local soil conditions, and sometimes also some other ground or earthquake characteristics that influence ground motion (see e.g. state of the art papers on attenuation equations by Douglas [4], Lee [5], or a paper by Lee and Manić [6]).
} 
where $N_{G R}(M)$ is the mean yearly rate of occurrence of earthquakes with magnitude greater than or equal to $M, a$ characterizes the mean yearly number of earthquakes, while $b$ describes the relative frequency of larger earthquakes to the smaller ones. If we assume that sizes (magnitudes) of earthquakes are temporally and spatially independent, and want to use such assumption for the estimation of the seismicity characteristics of the selected source zone, in that case the foreshocks and aftershocks should be first removed from the corresponding part of the seismic catalogue. Probability density function on magnitude for a double-truncated (bounded by limit magnitudes from both sides) Gutenberg-Richter recurrence relationship, can be further expressed (for a Poisson-distributed main shocks) as

$$
f_{m}(M)=\beta \frac{\exp \left[-\beta\left(M-M_{\min }\right)\right]}{1-\exp \left[-\beta\left(M_{\max }-M_{\min }\right)\right]}, \quad M_{\text {min }} \leq M \leq M_{\text {max }},
$$

where $M_{\min }$ and $M_{\max }$ are the lower and upper bounds on magnitude, $\beta$ is equal to $(\ln 10) b$, while the annual rate of earthquakes exceeding the magnitude $M_{\min }$ can be defined as

$$
v=\exp \left[a \ln 10-(b \ln 10) M_{\min }\right] .
$$

For the fault-specific sources it may be sometimes more appropriate to propose special time-varying distributions, while the time-invariant probability distribution as defined by Eq. (2) could still be used to describe the seismicity of areal source zones (which typically comprise a number of different faults). The temporal and spatial variations of the seismic potential can be incorporated into the seismic hazard analysis (refer e.g. to: $[10-11,13$, 1920]), but such analyses are feasible only when there are enough data [21].

The next step is to define the empirical attenuation relationships. The general form of the attenuation equations can be expressed as

$$
Y=f(M, R, P i),
$$

where $Y$ represents the selected ground motion parameter (e.g. peak ground acceleration, an ordinate of a response spectrum, duration of strong shaking, etc.), $M$ the magnitude or some other measure of the earthquake size, $R$ is the distance from the earthquake source to the site in question, while $P i$ represents all other parameters that describe earthquake source mechanism, seismic wave path effects, or local geology and soil characteristics, which will influence value of the used ground motion parameter at the given site. In order to develop an attenuation equation for a region or country, one has to possess a series of strong ground motion time histories recorded in that region. Using large number of such strong motion data, it is possible to derive the attenuation equation empirically. Hence, there is no definite, once for all, empirical attenuation equation, and these equations must be updated whenever significant number of new data for the region becomes available. Further, attenuation equations usually specify median amplitudes (i.e. the $50^{\text {th }}$ percentile values on the empirically obtained cumulative distribution function) while the scatter of the amplitude values around the median values is usually assumed to follow log-normal or a similar probability distribution. It is important to mention however that the probability distributions that are associated with the attenuation equations, are usually not truncated, and thereby the values of the chosen ground motion parameter that can be predicted by such equations are not limited [22]. Thus, the earthquake ground motions that are physically not conceivable for the real seismo-tectonic and geological conditions in the consid- 
ered region can still have a definite estimated probability of exceedance (in $t$ years). Having in mind that even very small probabilities can sometimes be required (e.g. for design or safety assessment of dams, nuclear power plants, long-span bridges, high-rise buildings, etc.), the upper bounds for the strong ground motion values that can be estimated by attenuation equations should be defined for each seismically active region or country. Definition of the upper bound ground motion values is an important issue for both the deterministic and probabilistic seismic hazard analysis [23], and has been recently discussed by a number of researchers from all over the world [24].

Now, if we for example follow the formulations of the PSHA method developed by Cornell [8] and McGuire $[9,12]$ and assume that the overall seismic hazard at a site is composed of the respective contribution from each source zone $i$ (out of the set of zones I), by using the so-called "theorem of total probability" [25], the mean annual rate of occurrence (that is the mean annual expected number) of the earthquakes that cause an amplitude Agmp of a ground motion parameter to exceed the expectation $A$, can be expressed as

$$
N(A)=\sum_{i \in I} v_{i} \int_{M_{0}}^{M_{\max }} \int_{R_{\min }}^{R_{\max }} G(\operatorname{Agmp}>A \mid M, R) f_{m_{i}}(M) f_{r_{i} \mid m_{i}}(R \mid M) d M d R,
$$

where $v$ indicates the annual rate of earthquakes exceeding the lower bound magnitude $M_{\min }, M_{\max }$ is the upper bound magnitude value, $R_{\min }$ and $R_{\max }$ define the bound values for the distance for each source zone; $G(\operatorname{Agm} p>A \mid M, R)$ denotes the conditional cumulative distribution function defining the probability that the expectation $A$ of the ground motion amplitude is exceeded under the condition that an event of magnitude $M$ occurred at distance $R$ (it is defined from the selected attenuation equation for the used ground motion parameter), $f_{m}$ denotes the probability density function on magnitude (see Eq. (2)), and $f_{r \mid m}$ is the probability density function on distance, which depends on the spatial relationship between the source and the site. Thus, to compute the seismic hazard at the chosen site, the contributions from the considered source zones are first integrated over all magnitudes and distances (inside the limits defined for a source zone), and then summed. If we further assume that all seismic events in the region (i.e. in all considered zones), are temporally and spatially independent, then by following the Poisson distribution [25] the probability of at least one exceedance of the expectation Agmp of a ground motion parameter of interest, in a period of 1 year (the so-called "annual" probability), can be calculated from

$$
P(A)=1-\exp [-N(A)],
$$

and this probability is considered to be time-independent. Furthermore, by using the socalled Binomial distribution [25] the probability $P_{t}(A)$ of at least one exceedance of the expectation $A$ in a period of $t$ years can be calculated as

$$
P_{t}(A)=1-[1-P(A)]^{t} .
$$

Calculations for $P(A)$ are usually performed for a certain number of expectation values $A$ of a strong ground motion parameter, and after that is done the interpolation is used to find the values of $A$ for the chosen probability levels. By fitting a curve to the calculated probabilities for a range of values $A$, one can create a hazard curve, $P($ Agmp $)$, for each investigated site. By further creating a closely spaced grid of sites covering the complete 
territory of a certain region, one is able to develop a whole seismic hazard map for a selected value of the probability $P(A)$ or $P_{t}(A)$, simply by contouring the sub-areas for which the values of $A$ fall in the same range (refer e.g. to: [26]).

Thus, the purpose of the PSHA is to calculate the probability of (no) occurrence, $P(A)$, and not the return period, defined as $T_{r}=N(A)^{-1}$, because such parameter does not have a clear physical meaning, regardless of the fact that it has been used by many researchers and also in Eurocode 8 [1] as an alternative way for the quantification of the seismic hazard. In other words, the return period, $T_{r}$, defined as the reciprocal value of the annual frequency of exceedance of a certain level of ground motion, cannot be directly converted into the definition of a single earthquake that will contribute most to the seismic hazard at a site, because the outputs of the PSHA analyses are composed of the respective contributions from all possible earthquakes that had been taken into account in the PSHA analysis. Earthquakes that contribute most to the hazard, i.e. to the calculated values of the probability, i.e. $P(A)$ or $P_{t}(A)$, can indeed be found and the process of decomposition of the PSHA estimates into the respective contributions of different seismic events is called the "de-aggregation" (of the seismic hazard) [27], and its purpose is to identify the "hazard-consistent" [28] earthquakes ${ }^{3}$. Beside the size and the location of the hazard-consistent earthquakes, by the de-aggregation procedure usually also some measure of the uncertainty is defined, like e.g. number of standard deviations from the median ground motion as predicted by a ground motion attenuation equation [27, 33], and the finding of the most appropriate de-aggregation procedure that includes the treatment of the uncertainties is still a subject of an extensive research (see e.g. [35-36]).

Now, in the case when the seismic hazard maps are expressed only by the values of the peak acceleration, beside the seismicity characteristics and geometrical distribution of plausible earthquake sources one has also to define an appropriate attenuation equation for estimation of the PGA values at a certain source-to-site distance and from a certain earthquake size, and the probabilistically estimated PGA values are then used for scaling design spectra of a normalized shape. However, if instead the attenuation equation for the PGA values, one uses the attenuation equations for different spectral amplitudes, then by applying completely the same PSHA procedure as for the PGA values, the probabilistic estimate can be found for each spectral ordinate and thus the Uniform Hazard Spectra can be derived. Expectations of all spectral UHS amplitudes will have the same probability of exceedance in one or in $t$ years. In the selection of the site specific response spectra for engineering design purposes it is important to have in mind that each earthquake (that can contribute to the seismic hazard at the site) may produce different spectral amplitudes and shapes. By combining seismic contributions from all considered sources and taking into account relative probabilities of occurrence of different earthquakes in each of those sources, the "uniform hazard spectra" are created [10-11, 13, 15, 37-40].

It is further important to remember that in a probabilistic seismic hazard analysis every probability of exceedance is obtained by considering all earthquakes in the region that can contribute to some extent to the seismic hazard at a site, and thereby any uniform

\footnotetext{
${ }^{3}$ These earthquakes can be identified in terms of ranges of magnitudes and distances [27, 29-32] for which the relative contribution to the corresponding hazard estimate, $P(A)$ or $P_{t}(A)$, is the largest, or in terms of the latitudes and longitudes, that define the locations of the earthquake sources, instead of the distances (e.g.: [33-34]) so that the predominant earthquakes can be directly identified in specific source zones or on specific active faults.
} 
hazard spectrum does not correspond to only one of those contributing earthquakes. In fact, the PSHA estimates of the strong ground motion at the same site and with the same probability level (annual or in $t$ years), but for different frequency ranges, are sometimes governed by earthquakes with significantly different magnitudes and/or source to site distances [41], and in general it is not possible to define one most contributing earthquake for all ordinates of a uniform hazard spectrum. Hence, strictly speaking, it would not be correct to apply a multimodal response spectrum structural analysis using the ordinates of a uniform hazard spectrum because one would then combine modal responses related to different particular predominant earthquakes, and strictly speaking, the UHS could/should be used only if the dynamic response of a structure can be modeled by a simple single-degree-of-freedom oscillator. Gupta [42] and Todorovska [43] have presented a method of how to carry out a seismic evaluation also of the multi-degree-of-freedom systems, at least for the structures with small modal damping and natural frequencies that are not too close, but such issues will remain out of the scope of current discussion. However, one could perform the disaggregation of the obtained PSHA estimates, and hence develop different earthquake scenarios and construct scenario response spectra and used them in the multimodal analyses. Considering that the earthquakes that contribute most to the PSHA estimates for the selected site usually have the predominant influence on the shapes of the estimated uniform hazard spectra, in some cases it could be still appropriate to use the Uniform Hazard Spectra themselves for the multi-modal response spectrum analyses, provided that the shapes of the UHS for the given site had been previously compared to the shapes of the corresponding UHS-consistent empirical scenario spectra and that no significant discrepancies between the two were found. Furthermore, accounting for the correlations between spectral ordinates at different response periods, the conditional mean spectrum (CMS) can also be constructed, as discussed in [44].

In this Paper and for the purposes of illustrating the relation between EC8, empirical and the uniform hazard spectra, we decided to use a slightly unconventional approach, and to create a series of the spectra scaled by using empirical scaling equations (the same as those used in the PSHA analysis for the creation of the UHS) for the magnitude and distance values of either the maximum credible or hazard-consistent earthquakes, i.e. for either the maximum plausible earthquake in the vicinity of the site or for the earthquakes that contribute most to the UHS ordinates for several chosen structural vibration periods.

We will now present an illustrative PSHA example in order to better explain former observations.

\section{AN ILLUSTRATION EXAMPLE - UNIFORM HAZARD SPECTRA FOR THE CITY OF BELGRADE}

In this Section, a simple illustrative example is presented where the Eurocode 8 [1] spectra have been compared to the uniform hazard spectra for the center of the city of Belgrade (the capital of the Republic of Serbia), shown in Fig. 1. Peak acceleration values and a series of spectral ordinates corresponding to periods up to $2.0 \mathrm{sec}$, for the location "Belgrade" have been calculated on the basis of the PSHA approach by using the "Cornell-McGuire" [8-9] method, i.e. EQRISK computer program. In the given example, the same input data were used as for the hazard analyses presented in two recent papers by Manić and Bulajić [45-46]. Considering that the purpose of the given example is not to propose any new national seismic hazard maps but simply to stress out the major issues 
regarding the shapes of the Eurocode 8 spectra, Uniform Hazard Spectra, and different empirical scenario spectra, the source zones were defined as the polygonal areal seismic source zones of a simplified shape (see Figure 1), with a uniform seismicity (both spatial and temporal) and the Poisson model of earthquake occurrence, and were delineated with respect to the data from the available catalogues of the occurred earthquakes, current hazard maps, areas that were suggested by Vukašinović (the director of the Seismological Survey of Serbia during the 1980s), and available active fault maps for the region ${ }^{4}$. As for the strong motion attenuation equations (Eq. 4), for this example we have used our new empirical equations for scaling response spectra in this region (the coefficients of which are given in Table 2a in Part I of this Paper [2]), in compliance with the Eurocode 8 that allows ([1]: Note 1 in Article 3.2.2.1(4) and Note 1 in Article 3.2.2.2(2)P) that countries who use or are going to use this book of regulations may define (in their National Annexes) spectra different than those that are already proposed.

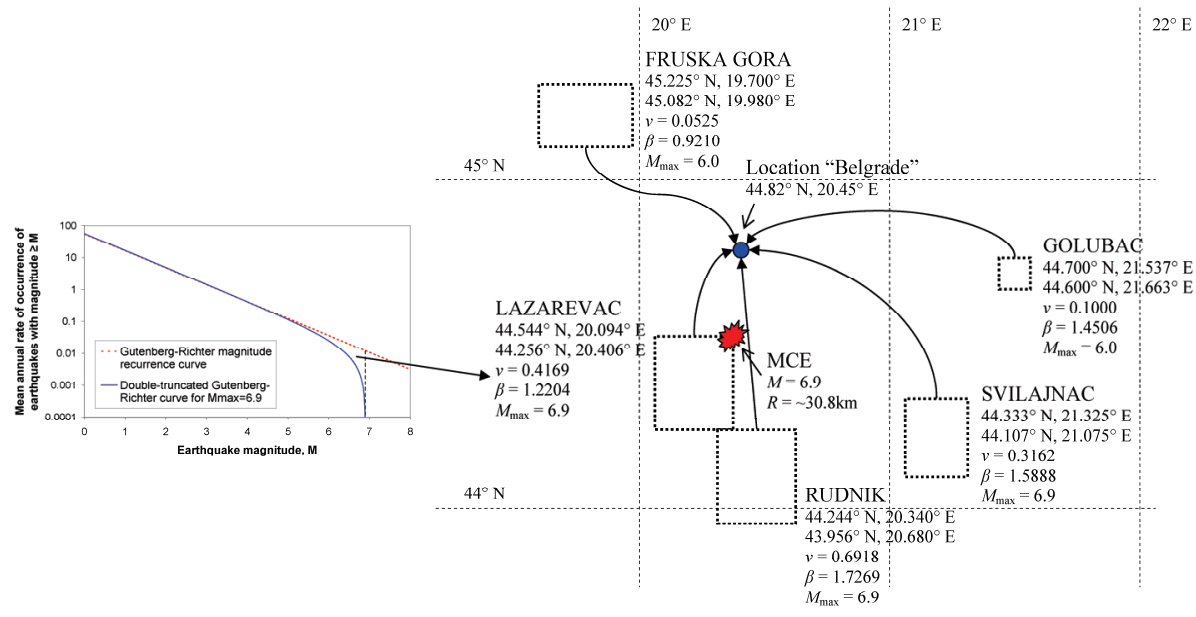

Fig. 1. Location for which the seismic hazard was estimated ("Belgrade"), the selected seismic source zones of a simplified shape with the magnitude recurrence relationship for the source zone "Lazarevac", and the source location of one (MCE) of the scenario events

Table 1 shows the values of the so-called "return periods", $T_{r}$, with the corresponding $P_{t}(A)$ values for $t=10$ and 50 years, and the corresponding annual probabilities, $P(A)$. As it has been already mentioned in Section 2, a standard misconception related to the PSHA estimates is that the return period, $T_{r}$, i.e. a parameter which in the case of the statistically independent set of seismic events can be defined as the reciprocal value of the annual fre-

\footnotetext{
${ }^{4}$ When the territory of Serbia is concerned, it is important to mention that the attenuation of the seismic waves coming from the intermediate-depth earthquakes inside the Vrancea's seismogenic zone (located inside the neighboring Romania) should be treated independently by applying a special attenuation equation (see, e.g. equation for the PGA values given by Musson [47] or the prediction equations for the whole spectra by Sokolov et al. [48]). Although it can be expected that the long-period waves from the Vrancea source could to some extent influence tall buildings in Belgrade this will remain outside the scope of the discussions given in this Paper.
} 
quency of exceedance $N(A)$, can be directly related to a single earthquake that has the mean recurrence time between two consecutive occurrences equal to $T_{r}$ years. However, the direct outputs of the probabilistic hazard analyses, i.e. the annual probabilities $P(A)$ or probabilities in $t$ years $P_{t}(A)$ that a certain level of ground motion will be exceed, are composed of the respective contributions of a series of earthquakes of different size, and with different hypocenters inside different source zones. In other words, every prospective earthquake in the considered region, regardless of its estimated size or the distance from the considered site, contributes to a certain amount to the probability that an amplitude of the analyzed ground motion parameter will exceed its target expectation, $A$. Hence, the "return period", $T_{r}$, (approximately linearly proportional to the reciprocal value of the calculated annual probability that a certain level of ground motion will be exceed, $\left.P(A)^{-1}\right)$ cannot be directly related to any specific prospective earthquake in the vicinity of the site, and has no clear physical meaning, while on the other hand can lead to misunderstanding of the PSHA results. Therefore, regardless of the fact that it has been used worldwide as an alternative parameter for the seismic hazard quantification, it might be advisable to exclude the very expression "return period, $T_{r}$ " from all regulations related to earthquake resistant design of structures, and thus also from the Eurocode 8 [1] terminology related to definition of the seismic action.

Figure 2 shows the hazard curves (estimated parameter vs. return periods) for the peak ground acceleration values and three selected spectral ordinates (at $0.2 \mathrm{~s}, 0.5 \mathrm{~s}$, and $1.0 \mathrm{~s}$ ) for the location "Belgrade" (Fig. 1) obtained by using the new set of regional empirical equations for scaling response spectra [2]. Figure 3 shows the Uniform Hazard Spectra i.e. spectral curves obtained by connecting different PSHA spectral estimates for the same annual probability. ${ }^{5}$ In the case of more detailed and thorough hazard analyses the so-called recursive analysis [49] would be performed where the dominant hazard sources are first identified in the PSHA analysis and than the corresponding deterministic events are modeled at a higher level of detail. In this manner the PSHA and DSHA analyses can be used complementary, allowing the probabilistic hazard analysis to guide the choice of the maximum credible event or a PSHAconsistent scenario event, and using the deterministic hazard estimates to refine the probabilistic ones (refer also to: [50-51]). In the presented illustrative example we decided to apply similar approach, only again in the simplified manner so as to remain focused on the relations between the Eurocode 8 spectra and the Uniform Hazard Spectra. Having in mind that among all of the defined seismic source zones in the adjacency of Belgrade (see Figure 1: Fruška Gora, Golubac, Lazarevac, Rudnik, and Svilajnac), the largest contributions to the PSHA results (and to the resulting UHS) comes from the Lazarevac zone (see the seismicity coefficient $\nu$ and $\beta$ in Fig. 1), ground motion for the maximum credible earthquake (MCE) spectra for the given location will be estimated simply by a "point source" model i.e. by scaling the attenuation equations for the distance of $\sim 30.8 \mathrm{~km}$ (i.e. the closest point to the location "Belgrade" of the northern edge of the Lazarevac source zone), and for the magnitude $M=6.9$ (the largest estimated value for the Lazarevac zone). ${ }^{6}$

\footnotetext{
${ }^{5}$ Uniform hazard spectral values were calculated at 13 ordinates: $T=0.00,0.05,0.075,0.10,0.15,0.20,0.30$, $0.40,0.50,0.75,1.00,1.50$, and 2.00 seconds, and interpolated between. In order to make comparisons of the UHS to the "deterministic" empirical spectra, the original "jagged" empirical spectra [2] were smoothed by drawing the same 13 discrete values and interpolating between.

${ }^{6}$ Such "point-source" deterministic estimates can in the case of location "Belgrade" indeed provide realistic strong motion predictions since the active fault maps available to the authors showed that the angle between the source-to-site vector and the direction of rupture propagation is large enough for the most important faults, i.e. for the given location there is no danger of the significant "directivity" [52-53] effects.
} 

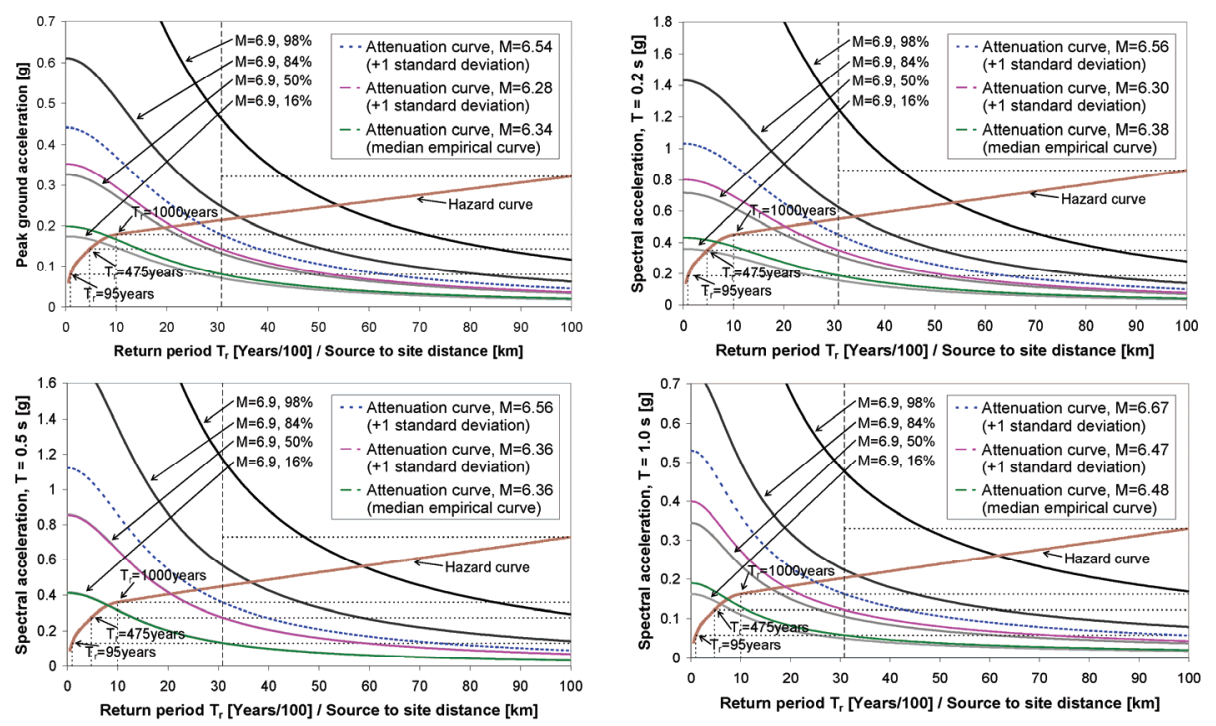

Fig. 2. Seismic hazard curves and the de-aggregation pattern for different spectral ordinates, obtained by using empirical scaling equations for the north western Balkans

Table 2. Set of the corresponding values for different probabilistic seismic hazard measures: a) $P(A)$ are the probabilities of at least one exceedance of the expectation $A$ of a ground motion parameter in the period of one year, b) $P_{10}(A)$ and c) $P_{50}(A)$ are the probabilities of at least one exceedance of $A$ in the time period of 10 and 50 years, respectively, and d) $T_{r}(A)$ denotes the values of the so-called "return periods"

\begin{tabular}{cccc}
\hline$P(A)$ & $P_{10}(A)[\%]$ & $P_{50}(A)[\%]$ & $T_{r}(A)=\frac{1}{N(A)} \cong \frac{1}{P(A)}=\frac{1}{1-\sqrt[t]{1-P_{t}(A)}}[$ years $]$ \\
\hline 0.020000 & 18.29 & $* 63.58$ & 50 \\
0.010481 & 10 & 40.95 & 95.41 (EC8 “damage limitation" requirement) \\
0.005000 & 4.89 & 22.17 & 200 \\
0.002105 & 2.09 & 10 & 475.06 (EC8 “no-collapse" requirement) \\
0.001000 & 1.00 & 4.88 & 1000 \\
0.000100 & 0.10 & 0.50 & 10,000
\end{tabular}

* The probability values of at least one exceedance of the expectation $A$ in the period of $T_{r}$ years (i.e. in the time period of the return period itself) rapidly decrease from $100 \%$ for $T_{r}=1$ year to $75 \%$ for $T_{r}=2$ years, than gradually decrease and are equal to $\sim 63 \%$ for all return periods $T_{r}$ larger than $\sim 50$ years.

Figure 2 shows the empirical attenuation curves for different spectral ordinates and for the MCE magnitude of 6.9 (the largest estimated magnitude in the closest source zone), for the median minus one standard deviation empirical estimates (i.e. the 16 percentile), median (50\%), median plus one standard deviation (84\%) and median plus two standard deviations empirical estimates (98\%), and compares those empirical attenuation curves to 
the obtained probabilistic hazard curve. Furthermore, Fig. 2 also shows several another attenuation curves that are iteratively obtained by changing value of the magnitude so that at the distance of the MCE event $(\sim 30.8 \mathrm{~km})$ selected spectral ordinate will have the same value as on the hazard curve (i.e. on the UHS) for the return periods, $T_{r}$, of 95,475 and 1000 years. Fig. 3 further shows the corresponding UHS and empirical scenario spectra.

As it can be seen from Fig. 2, the scenario event (inside the closest source zone) that will contribute the most to the estimated seismic hazard at the given site, will occur at the distance between $\sim 30.8$ and $\sim 102 \mathrm{~km}$, and will have the magnitude lower than 6.9 while the empirical reliability level will lie between those of the closest two MCE attenuations curves. For example, the most contributing event for the UHS ordinate at the vibration period of $0.2 \mathrm{~s}$, and for the $P_{t}(A)=10 \%$ in $t=50$ years (the return period $T_{r}$ of 475 years), would occur at the distance up to $\sim 51 \mathrm{~km}$ from the given site in the case of the empirical estimates between $50 \%$ and $84 \%$ reliability, at the distance between $\sim 51 \mathrm{~km}$ and $\sim 85 \mathrm{~km}$ for the empirical estimates between $84 \%$ and $98 \%$ reliability, and at larger source to site distances for even larger percentile (and less reliable) empirical estimates. Obviously, the UHS-compatible empirical scenario spectra depend on the probability that the empirical estimates shall not be exceeded - for the $T_{r}=95$ years UHS spectra, and for some of the vibration periods and scaling equations, already the $16 \%$ empirical spectra will be able to reach the values of the corresponding UHS ordinates, for the $T_{r}=475$ and 1000 years UHS the 84 percentile empirical estimates should be used, while for the $T_{r}=10,000$ years UHS not even the $84 \%$ empirical estimates will suffice but the $98 \%$ (i.e. median plus two standard deviations) empirical estimates should be used. Large empirical reliability levels (e.g. median plus 2, 3 or even 4 standard deviations estimates) that are needed in the case of the hazard estimates with very low probabilities $P(A)$ and $P_{t}(A)$, indicate that these hazard values (and the corresponding UHS), are overly dominated by the $\sigma$ value of the used empirical attenuation equation (see Eqs. 1 and 2 in [2]) i.e. by the scatter of the used strong motion data around median empirical estimates. Just like most available empirical attenuation equations, our new empirical scaling equations [2] (used in this example) do not define any bounds for the probability distributions that define this scatter and thus finite probabilities are obtained even for the unrealistically large ground motion estimates. As we already said in Section 2, the definition of the upper bound ground motion values is an important issue for both the deterministic and probabilistic seismic hazard analysis. However, and notwithstanding the excessive contribution of the standard deviation in the strong-motion prediction equations, caution needs to be applied before applying any truncations to the distribution of the ground-motion residuals, as explained in the paper by Strasser et al. [54].

Since we defined the seismic source zones (see Fig. 1) as the polygonal areal zones of a simplified shape, with a uniform spatial seismicity and the Poisson model of earthquake occurrence, for the purposes of the illustrative example we will define the UHS-consistent scenario events so as to have the epicenter at the same spot of the MCE event (at $\sim 30.8$ $\mathrm{km}$ from the given site) while the magnitude will be iteratively found so that it be the first one less than 6.9 for which the empirical estimate (for the lowest possible empirical reliability) will match the corresponding UHS ordinate. From Fig. 2 it can be seen for example that the magnitude values of the PSHA-consistent scenario events for the PGA values are equal to 6.34 (the $50 \%$ i.e. the median empirical estimate) for $T_{r}=95$ years, to 6.28 (the $84 \%$ i.e. median plus one standard deviation empirical estimate) for $T_{r}=475$ years, 
and to 6.54 (again the $84 \%$ empirical estimate) for $T_{r}=1000$ years $\left(P_{t}(A)=\sim 4.88 \%\right.$ in $\mathrm{t}=$ 50 years), while e.g. for the UHS amplitude at $\mathrm{T}=0.5 \mathrm{~s}$ the corresponding scenario event magnitudes are equal to 6.36 (the median estimate) for $T_{r}=95$ years, to 6.36 (the $84 \%$ empirical estimate) for $T_{r}=475$ years, and to 6.56 (the $84 \%$ empirical estimate) for $T_{r}=$ 1000 years. By observing different plots in Fig. 2 it is thus obvious that not only that the magnitude of the UHS-consistent scenario events change with spectral ordinates (due to different strong motion attenuation features for different vibration periods), but also that these magnitudes often pertain to different probabilities of the empirical estimates.
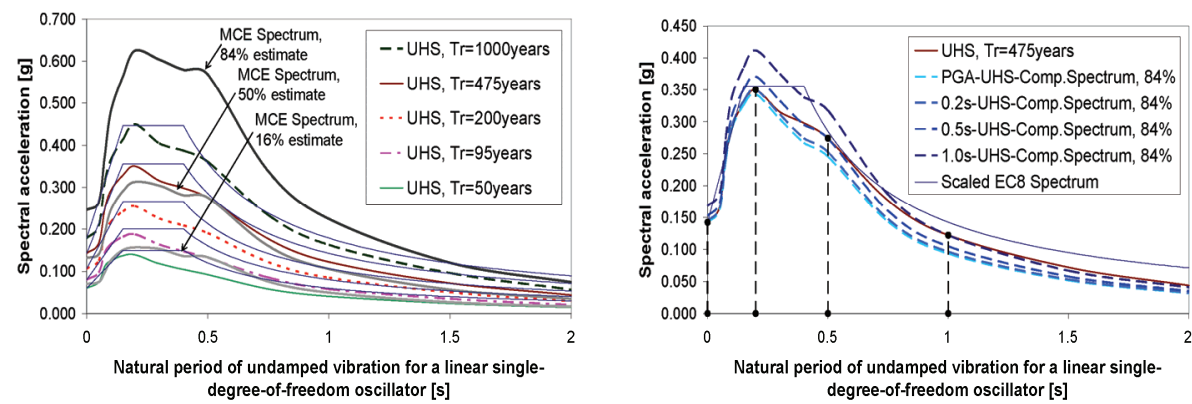

Fig. 3. Uniform hazard spectra for the location "Belgrade" and the maximum credible earthquake spectra (left part) i.e. the $T_{r}=475$ years uniform hazard spectrum and the UHS-compatible empirical spectra for different spectral ordinates (right part), vs. EC 8 elastic spectra scaled by corresponding PSHA estimates of the peak ground acceleration.

Left part of Fig. 3 shows the obtained Uniform Hazard Spectra for $T_{r}=95,200,475$, 1000 , and 10,000 years and the $16 \%$, median (50\%) and $84 \%$ empirical spectra for the "maximum credible earthquake" (MCE), i.e. the closest to the considered site and the strongest of all prospective earthquakes that have been taken into account in the PSHA analysis (i.e. for calculation of the uniform hazard spectra). Right part of the same Fig. 3 shows the 475 years Uniform Hazard Spectrum and the corresponding UHS-compatible empirical scenario spectra for different spectral ordinates. Left part of Fig. 3 also shows the Eurocode 8 elastic spectra scaled by the $T_{r}=95,200,475,1000$, and 10,000 years PSHA estimates of the peak ground acceleration (PGA), and right part of Fig. 3 shows only the Eurocode 8 spectrum scaled by the $T_{r}=475$ PSHA estimate of PGA. From Fig. 3 it can be seen that although the shapes of the calculated Uniform Hazard Spectra do resemble the shapes of the corresponding scenario spectra, they are still not the same (the differences between corresponding ordinates of UHS-consistent spectra and of the UHS go up to $\sim 17 \%$ ). Clearly, this is because the value of each UHS ordinate comprises many contributions from different empirical spectra scaled for various values of earthquake magnitudes and source to site distances. It can be also seen from Fig. 3 (right part) that the UHS-compatible empirical spectra can in some cases have significantly different shapes themselves. Furthermore, although recent seismic hazard analyses in the USA [55] and in Canada [56-57] showed that only a few spectral ordinates are sufficient to construct the spectra that will closely match the shape of the uniform hazard spectra, namely: 
$0.1,0.3,0.5,1.0$, and $2.0 \mathrm{sec}$ for the USA, and $0.2,0.5,1.0$, and $2.0 \mathrm{sec}$ for Canada, it seems that the choice of how many and which one of the spectral ordinates are sufficient for definition of the Uniform Hazard Spectra in some country (or a region) cannot be made before the responsible national authorities make the exact choice of the empirical equation(s) that will be used for scaling different spectral ordinates, and of course not before a thorough analysis of the UHS shapes for a series of different sites in the considered region.

\section{DISCUSSION AND CONCLUSIONS}

Shape of the Eurocode 8 [1] elastic spectrum, $S_{\mathrm{e}}(T)$, is selected with respect to the magnitude of the earthquakes "that will contribute most to the seismic hazard defined for the purpose of probabilistic hazard assessment, rather than on basis of the conservative upper limits (e.g. the Maximum Credible Earthquake) defined for that purpose" ([1]: Note 2 in Article 3.2.2.1(5) and Note 1 in Article 3.2.2.2(2)P). This definition is however somewhat obscure since the spectral shape is to be chosen with respect to the magnitudes of only one or just a few earthquakes that dominantly influence the probabilistic seismic hazard estimate at a given site (Type 1 or Type 2 spectrum), while the whole spectrum is scaled by the value of the peak ground acceleration that should be found for the given site on an appropriate seismic hazard map, and which is obtained as a result of a complete probabilistic hazard analysis i.e. taking into account all prospective earthquakes in the considered region. These "most contributing" earthquakes will be in general case different (i.e. of different size and at a different distance from the given site) for different spectral ordinates, while the Eurocode 8 [1] spectrum is scaled by using only the PSHA estimate of the peak acceleration value. Furthermore, Eurocode 8 does not consider that the shape of the design spectra are also related to the reliability level of the empirical estimates - for the probabilistic seismic hazard estimates with smaller probability in $t$ years the empirical predictions with lower reliability level of the empirical estimates will "contribute most" to the UHS results.

In this Paper we presented an illustrative example where the EC8 spectra are for a site in the city of Belgrade (Serbia) compared to the created UHS spectra, as well as to the empirical spectra scaled by different scenario earthquake parameters.

Results indicate that the use of Eurocode 8 response spectra may in some cases lead to underestimation and in other cases to overestimation of the design seismic action, i.e. that it can lead to grossly un-conservative or even to over-conservative seismic design. Presented results thus advocate that in Serbia and the whole north-western Balkans the reliable regional empirical attenuation equations should be used to create UHS spectra for a dense network of sites, so that UHS spectra can be used for definition of seismic action.

\section{REFERENCES}

1. Eurocode 8 (2004). Design of structures for earthquake resistance, Part I: General rules, seismic actions and rules for buildings, EN 1998-1, CEN - European Committee for Standardization, Brussels.

2. Bulajić, B.Đ, M.I. Manić, and Đ. Lađinović (2012). Towards preparation of design spectra for Serbian National Annex to Eurocode 8 - Part I: spectral shapes and regional empirical equations for scaling pseudo-acceleration spectra, Facta Universitatis, Series: Architecture and Civil Engineering, in press.

3. Richter, C.F. [1958] Elementary Seismology, W.H. Freeman, San Francisco. 
4. Douglas, J. (2003). Earthquake ground motion estimation using strong motion records: A review of equations for the estimation of peak ground acceleration and response spectral ordinates, Earth-Science Reviews, Vol. 61, pp. 43-104.

5. Lee, V.W. (2002). Empirical scaling of strong earthquake ground motion - Part I: Attenuation and scaling of response spectra, ISET Journal of Earthquake Technology, Paper No. 425, Vol. 39, No. 4, pp. 219-254.

6. Lee, V.W. and M.I. Manić (2009). Empirical scaling of strong earthquake ground motion in the former Yugoslavia - a review, Izgradnja, Vol. 63, No. 5-6, pp. 155-158.

7. Bulajić. B. and M. Manić (2006). Selection of the appropriate methodology for the probabilistic seismic hazard analysis on the territory of the Republic of Serbia, Facta Universitatis, Series: Architecture and Civil Engineering, Vol. 4, No. 2, pp. 101-113, University of Niš, Republic of Serbia.

8. Cornell, C.A. (1968). Engineering seismic risk analysis, Bulletin of the Seismological Society of America, Vol. 58, No. 5, pp. 1583-1606.

9. McGuire, R.K. (1976). Fortran computer program for seismic risk analysis, Technical Report 76-77, US Geological Survey Open File Report.

10. Anderson, J.G. and M.D. Trifunac (1977). Uniform risk functionals for characterization of strong earthquake ground motion, Report No. 77-02, Department of Civil Engineering, University of Southern California, Los Angeles, California.

11. Anderson, J.G. and M.D. Trifunac (1978). Uniform risk functionals for characterization of strong earthquake ground motion, Bulletin of the Seismological Society of America, Vol. 68, No. 1, pp. 205-218.

12. McGuire, R.K. (1993). Computations of seismic hazard, Annali di Geofisica, Vol. 36, pp. 181-200.

13. Lee, V.W. and M.D. Trifunac (1985). Uniform risk spectra of strong earthquake ground motion: NEQRISK, Report No. 85-05, Department of Civil Engineering, University of Southern California, Los Angeles, California.

14. Gupta, I.D. (2002). The state of the art in seismic hazard analysis, ISET Journal of Earthquake Technology, Vo. 39, No. 4, pp. 311-346.

15. Anderson, J.G., M.D. Trifunac, and V.W. Lee (1987). Methods For Introduction Of Geological Data Into Characterization Of Active Faults And Seismicity And Upgrading Of The Uniform Risk Spectrum Technique, U.S. Nuclear Regulatory Commission, Washington, D.C., Report NUREG/CR-4903, Vol. 2.

16. Anderson, J.G. (1979). Estimating the seismicity from geological structures for seismic risk studies, Bulletin of the Seismological Society of America, Vol. 69, No. 1, pp. 135-158.

17. Anderson, J.G. (1981). A simple way to look at a Bayesian model for the statistics of earthquake prediction, Bulletin of the Seismological Society of America, Vo. 71, No. 6, pp. 1929-1931.

18. Gutenberg, B. and C. Richter (1944). Frequency of earthquakes in California, Bulletin of the Seismological Society of America, Vol. 34, No. 4, pp. 185-188.

19. Lee, V.W. (1992). On strong motion uniform risk functionals computed from general probability distributions of earthquake recurrences, Soil Dynamics and Earthquake Engineering Vol. 11, No.6, pp. 357-367.

20. Todorovska, M.I. (1994). Comparison of response spectrum amplitudes from earthquakes with lognormally and exponentially distributed return periods, Soil Dynamics and Earthquake Engineering, Vol. 13, No. 2, pp. 97-116.

21. Secanell, R., X. Goula, T. Susagna, J. Fleta, and A. Roca (2004). Seismic hazard zonation of Catalonia, Spain, integrating random uncertainties, Journal of Seismology, Vol. 8, pp 25-40.

22. Bender, B. (1984). Incorporating acceleration variability into seismic hazard analysis, Bulletin of the Seismological Society of America, Vol. 74, No. 4, pp. 1451-1462.

23. Bommer, J.J. (2002). Deterministic vs. probabilistic seismic hazard assessment: an exaggerated and obstructive dichotomy, Journal of Earthquake Engineering, Vol. 6 (Special Issue No. 1), pp. 43-73.

24. Bommer, J.J., N.A. Abrahamson, F.O. Strasser, A. Pecker, P.-Y. Bard, H. Bungum, F. Cotton, D. Fäh, F. Sabetta, F. Scherbaum, and J. Studer (2004). The challenge of defining upper bounds on earthquake ground motions, Seismological Research Letters, Vol. 75, No. 1, pp. 82-95.

25. Ang, A.H. and W.H. Tang (2006). Probability Concepts in Engineering: Emphasis on Applications to Civil and Environmental Engineering, John Wiley \& Sons.

26. Trifunac, M.D. and V.W. Lee (1987). Microzonation of a metropolitan area, Report No. 87-02, Department of Civil Engineering, University of Southern California, Los Angeles, California.

27. McGuire, R.K. (1995). Probabilistic seismic hazard analysis and design earthquakes: Closing the loop, Bulletin of the Seismological Society of America, Vol. 85, No. 5, pp. 1275-1284. 
28. Ishikawa, Y. and H. Kameda (1988). Hazard consistent magnitude and distance for extended seismic risk analysis, Proc. of the 9th World Conference on Earthquake Engineering, Vol. 2, Tokyo, Japan, pp. 89-94.

29. McGuire, R.K. and K.M. Shedlock (1981). Statistical uncertainties in seismic hazard evaluations in the United States, Bulletin of the Seismological Society of America, Vol. 71, No. 4, pp. 1287-1308.

30. Cramer, C.H. and M.D. Petersen (1996). Predominant seismic source distance and magnitude maps for Los Angeles, Orange, and Ventura Counties, California, Bulletin of the Seismological Society of America, Vol. 86, No. 5, pp. 1645-1649.

31. Harmsen, S., D. Perkins, A. Frankel (1999). Deaggregation of probabilistic ground motions in the central and eastern United States, Bulletin of the Seismological Society of America, Vol. 89, No. 1, pp. 1-13.

32. Solnes, J., R. Sigbjörnsson, and J. Eliasson (2004). Probabilistic seismic hazard mapping of Iceland: Proposed seismic zoning and de-aggregation mapping for EUROCODE 8, Proc. of the $13^{\text {th }}$ World Conference on Earthquake Engineering, Vancouver, B.C., Canada, Paper No. 2337.

33. Bazzurro, P. and C.A. Cornell (1999). Disaggregation of seismic hazard, Bulletin of the Seismological Society of America, Vol. 89, No. 2, pp. 501-520.

34. Harmsen, S. and A. Frankel (2001). Geographic deaggregation of seismic hazard in the United States, Bulletin of the Seismological Society of America, Vol. 91, No. 1, pp. 13-26.

35. Harmsen, S.C. (2001). Mean and modal $\varepsilon$ in the deaggregation of probabilistic ground motion, Bulletin of the Seismological Society of America, Vol. 91, No. 6, pp. 1537-1552.

36. Takada, T. and S. Ochi (2004). Probability-based determination of design earthquakes, IFED International The First Forum on Engineering Decision Making, Stoos, Switzerland, accessed on 5 June 2010 at http://www.ifed.ethz.ch/events/firstforum.html.

37. Anderson, J.G. (1978). Program EQRISK: A computer program for finding uniform risk spectra of strong earthquake ground motion, Report No. 78-11, Department of Civil Engineering, University of Southern California, Los Angeles, California.

38. Anderson, J.G. and M.D. Trifunac (1979). A Note on Probabilistic Computation of Earthquake Response Spectrum Amplitudes, Nuclear Engineering and Design, Vol. 51, No. 2, pp. 285-294.

39. Todorovska, M.I. (1995a). Uniform probability response spectra for selecting site specific design motions, Proc. Of the Third Int. Conf. on Recent Advances in Geotechnical Earthquake Engineering and Soil Dynamics, Theme 8- Seismology: Predicting strong ground motion for design, Vol. II, St. Louis, Missouri, USA, pp. 613-618.

40. Todorovska, M.I. (1995b). Effects of earthquake source parameters on uniform probability response spectra, Proc. of the 10th European Conference on Earthquake Engineering, Vol. 4, Vienna, Austria, pp. 2579-2584.

41. Trifunac, M.D. (1989). Threshold magnitudes which cause ground motion exceeding the values expected during the next 50 years in a metropolitan area, Geofizika, Vol. 6, pp. 1-12.

42. Gupta, I.D. (1994). A probabilistic approach for estimating the response of multi-degree-of-freedom structures, Soil Dynamics and Earthquake Engineering, Vol. 13, No. 2, pp. 79-87.

43. Todorovska, M.I. (1995c). A note on distribution of amplitudes of peaks in structural response including uncertainties of the exciting ground motion and of the structural model, Soil Dynamics and Earthquake Engineering, Vol. 14, No. 3, pp. 211-217.

44. Baker, J.W. and C.A. Cornell (2006). Spectral shape, epsilon and record selection, Earthquake Engineering and Structural Dynamics, Vol. 35, pp. 1077-1095.

45. Manić, M.I. and B.Đ. Bulajić (2006). Deterministic and probabilistic seismic hazard assessment for the wider territory of the city of Belgrade, Izgradnja, Vol. 60, No. 11-12, pp. 289-305 (In Serbian with English abstract).

46. Manić, M.I. and B.Đ. Bulajić (2007). Parametric analysis of the probabilistic seismic hazard assessment for the wider territory of the city of Belgrade, Izgradnja, Vol. 61, No. 3-4, pp. 113-130 (In Serbian with English abstract).

47. Musson, R. (1999). Probabilistic seismic hazard maps for the North Balkan region, Annali di Geofisica, Vol. 42, pp. 1109-1124.

48. Sokolov, V., K.-P. Bonjer, F. Wenzel, B. Grecu, and M. Radulian (2008). Ground-motion prediction equations for the intermediate depth Vrancea (Romania) earthquakes, Bulletin of Earthquake Engineering, Vol. 6, No. 3, pp. 367-388.

49. McGuire, R.K. (2001). Deterministic vs. probabilistic earthquake hazards and risks, Soil Dynamics and Earthquake Engineering, Vol. 21, No. 5, pp. 377-384. 
50. Anderson, J.G. (1997). Benefits of scenario ground motion maps, Engineering Geology, Vol. 48, No. 1, pp. $43-57$.

51. Anderson, J.G., J.N. Brune, R. Anooshehpoor, and S. Ni (2000). New ground motion data and concepts in seismic hazard analysis, Current Science, Vol. 79, No. 9, pp. 1278-1290.

52. Joyner, W. and D. Boore (1988). Measurement, characterization, and prediction of strong ground motion, in Earthquake Engineering and Soil Dynamics II, Recent Advances in Ground-Motion Evaluation, ed. J.L. Von Thum, Geotechnical Special Publication No. 20, American Society of Civil Engineers, pp. 43-102.

53. Guatteri, M., P. Mai, G. Beroza, and J. Boatwright (2002). Strong ground motion prediction from stochastic-dynamic source models, Bulletin of Seismological Society of America, Vol. 93, No. 1, pp. 301-313.

54. Strasser, F.O., J.J. Bommer, and N.A. Abrahamson (2008). Truncation of the distribution of groundmotion residuals, Journal of Seismology, Vol. 12, No. 1, pp. 79-105.

55. Frankel, A.D., M.D. Petersen, C.S. Mueller, K.M. Haller, R.L. Wheeler, E.V. Leyendecker, R.L. Wesson, S.C. Harmsen, C.H. Cramer, D.M. Perkins, and K.S. Rukstales (2002). Documentation for the 2002 update of the national seismic hazard maps, Open-File Report 02-420, US Geological Survey, Denver, Colorado.

56. Adams, J. and G.M. Atkinson (2003). Development of seismic hazard maps for the 2005 National Building Code of Canada, Canadian Journal of Civil Engineering, Vol. 30, pp. 255-271.

57. Adams, J. and S. Halchuk (2004). Fourth-generation seismic hazard maps for the 2005 National Building Code of Canada, Proc. of the $13^{\text {th }}$ World Conference on Earthquake Engineering, Vancouver, B.C., Canada, Paper No. 2502.

\section{KA PRIPREMI PROJEKTNIH SPEKTARA ZA SRPSKI NACIONALNI ANEKS NA EVROKOD 8 - DEO II: PRIMENA UHS PRISTUPA UMESTO SKALIRANJA EMPIRIJSKI DEFINISANIH SPEKTRALNIH OBLIKA JEDNIM PSHA PARAMETROM}

\section{Borko Đ. Bulajić, Miodrag I. Manić, Đorđe Lađinović}

Evrokod 8 spektri se skaliraju sa vrednostima maksimalnog ubrzanja tla koje su određene za zadatu lokaciju kroz probabilističku analizu seizmičkog hazarda (PSHA). Međutim, spektri koji nastaju kombinovanjem empirijskih oblika sa jednim jedinim PSHA faktorom za skaliranje, neće predstavljati tzv. Uniform Hazard Spektre (UHS). Štaviše, sam oblik (Tip 1 ili Tip 2) elastičnog spectra po Evrokodu 8 se bira u odnosu na magnitude zemljotresa "koji će najviše doprineti seizmičkom hazardu određenom za potrebe probabilisticke ocene hazarda...". Ovakva definicija je donekle nejasna jer su ovi zemljotresi "koji će najviše doprineti" ( period", različiti za različite periode vibracija, dok se ceo Evrokod 8 spektar skalira korišćenjem samo PSHA ocene maksimalnog ubrzanja tla. U ovom radu predstavljamo jedan jednostavan ilustrativni primer Uniform Hazard Spektara za Beograd i poredimo dobijene UHS spektre, kao i scenario empirijske spektre skalirane za različite zemljotresne parametre, sa odgovarajućim spektrima po Eurokodu 8, dalje potencirajući suštinske nedoslednosti u postojećim sugestijama Evrokoda 8 u pogledu kreiranja projektnih spektara.

Ključne reči: Evrokod 8, skaliranje spektara, probabilistička analiza seizmičkog hazarda, povratni period, Uniform Hazard Spektri. 